\title{
Reproductive Intentions of HIV-Positive Women on ARV Treatment in Abia State, Southeast Nigeria
}

\author{
Ijeoma Nduka, ${ }^{1}$ Ezinna Ezinne Enwereji, ${ }^{2}$ Enyinnaya C. Nduka, ${ }^{3}$ and Reginald Ahuizi Eke ${ }^{2}$ \\ ${ }^{1}$ Department of Community Medicine, Niger Delta University, Wilberforce Island, Amassoma, Bayelsa State, Nigeria \\ ${ }^{2}$ College of Medicine, University Teaching Hospital, Abia State University, Uturu, Aba, Abia State, Nigeria \\ ${ }^{3}$ Department of Obstetrics and Gynaecology, Federal Medical Center, Umuahia, Abia State, Nigeria
}

Correspondence should be addressed to Ezinna Ezinne Enwereji; hersng@yahoo.com

Received 19 December 2013; Accepted 9 January 2014; Published 20 February 2014

Academic Editors: J. Konde-Lule and A. R. Mawson

Copyright (C) 2014 Ijeoma Nduka et al. This is an open access article distributed under the Creative Commons Attribution License, which permits unrestricted use, distribution, and reproduction in any medium, provided the original work is properly cited.

\begin{abstract}
Introduction. In the African culture, the primary reason for marriage is procreation. Every female strives to perform this role irrespective of her health status so as to fulfill part of the conditions for maintaining the marriage. The question is, to what extent are HIV-positive women aware of the risks of fulfilling this role? The study aimed to determine the reproductive intentions of HIV-positive women in Abia State. Materials and Methods. This was a longitudinal cross-sectional descriptive study conducted among married HIV-positive women attending the Heart to Heart treatment centre in Abia State University Teaching Hospital from February to October 2013. Systematic sampling was used to select 250 married women between the ages of 15-49 years who are on antiretroviral therapy. Interviewer administered questionnaire and focus group discussion were used to obtain relevant information from the participants. Data were analysed qualitatively and quantitatively. SPSS version 17 software was also used in the analyses. Results. The mean number of living children of the respondents was $2.3 \pm 4.7$. A good proportion of the respondents, $158(63.7 \%)$ the desired to have more children. The younger the age group of the respondents $(\mathrm{OR}=7.33)$, the lower their parity (OR $=3.69)$ and more regular they attended ARV clinic $(O R=47.76)$ the more they desired to have more children. The main reason for desiring more children was the quest to have male children. In the words of one respondent, "without a male child, the marriage is not secure. The woman can be chased out at any time." Conclusion. The fact that a large proportion of HIV-positive women, irrespective of the mean number of living children and their gender, still desired to have more children shows poor knowledge of the risk they are exposed to by having large number of children. Family counseling/education on the benefits of using family planning devices especially condom is necessary for HIV-positive women and their male partners.
\end{abstract}

\section{Introduction}

The global HIV/AIDS pandemic has continued to constitute serious health and socioeconomic challenges in many countries especially the developing countries. Globally, 34.0 million people were living with HIV at the end of 2011; of these, 22.5 million (69\%) live in sub-Saharan Africa [1]. In 2011, 1.7 million people died from several causes including pregnancy [1].

In Nigeria, since the first case of AIDS was reported in 1986 [2], the epidemic has continued to evolve. Nigeria like any other developing country has experienced a reversal in health and developmental gains over these past three decades. This is reflected in indices such as life expectancy at birth and infant mortality among others [3]. About 2.98 million adults live with HIV and AIDS in Nigeria and $4.1 \%$ of them are pregnant women [3].

Nigeria is the most populous country in Africa [4] with high value placed on having large number of children. In many Nigerian communities, especially where farming is the predominant occupation, having large number of children is of great importance. The burden of nurturing large number of children is placed on the women. Culturally, there are two main reasons a man should divorce a wife. First, if she fails to 
conceive few months after marriage and second if she fails to have male children. To satisfy these obligations, women strive to have babies especially male babies so as to secure the marriage. When a married woman is unable to satisfy these expectations, the man is entitled to either divorce the wife or marry many more women to fulfill these obligations. This act of the man having many other women to procreate can boost promiscuity and thereby increase the risk of sexually transmitted infections including HIV. On the other hand, the women are faced with the pressure of having more children irrespective of their health status.

Reproductive issues among people living with HIV and AIDS are attracting recent attention in research $[5,6]$. The progress made in the provision of antiretroviral treatment for people living with HIV and AIDS has improved pregnancy outcome and reduced transmission from mother to child to about 2\% [7]. This has led to a reverse in the reproductive intentions of HIV-positive women in developed countries as many more women are not considering childbearing as the primary aim of marriage [8]. However, some countries with high HIV prevalence still provide limited access to HIV treatment and support. This limited access leaves the diverse reproductive and family planning needs of people living with HIV and AIDS in these countries unmet. More than $80 \%$ of women living with HIV are still in their reproductive age and this increases the possibility of such women desiring to have children. The desire to have children among HIV-positive women has significant implications on the transmission of the virus even to the unborn child [911]. This means that women are faced with the complex decision of having babies who might be HIV-positive. They are also faced with risk of transmitting the virus to significant others who might be HIV-negative. This shows that fertility desires and outcomes of HIV-positive women are froth with risks unlike those of their HIV-negative counterparts [12-14].

Studies have shown that HIV-positive women experience more complications than their HIV-negative counterparts. They have higher risk pregnancies and deliveries from anemia and others due to infections, bleedings, and miscarriages. They are also faced with increased risk of dying from tuberculosis [15-17]. Although the risk of mother to child transmission is reduced by prophylactic treatment, it is a well documented fact that maternal transmission accounts for almost all new infections in children $[15,18]$. The fact is that the risks of HIV transmission will keep increasing as long as HIV-positive women desire to have children. There is need to encourage HIV-positive women to use family planning services to limit the number of children they will have so as to reduce the risk of exposing their children to orphans or the problems of foster care and support $[16,19,20]$. This study aimed to discourage HIV-positive women from having large number of babies by health-educating them on the benefits of family planning practices.

Studies have identified the main motivating factors for HIV-positive women desiring to have large number of babies. Factors identified include the quest to have male children and the need to keep the marriage and to satisfy husband's desire. In a study conducted in Nigeria, it was found that $68 \%$ of
HIV-positive women who had more children did so just to keep their marriages $[18,21]$. In a similar study with $490 \mathrm{HIV}$ positive women in Ontario, Canada, 69\% had more babies while $58 \%$ intended to become pregnant in future [17].

The increased desire of HIV-positive women especially in developing countries to have more babies irrespective of the possible health hazards made researchers recommend the following: that governments of nations should ensure that drugs and other logistics needed to protect the unborn child from transmission of the virus are accessible and affordable, that the health care providers should assist HIV-positive women to plan for safer pregnancies so as to protect their health and vertical transmission, and also that clinicians should health educate clients regularly on general preconception guidelines, prenatal care, appropriate use of ART during pregnancy, and strategies to increase pregnancy success to reduce horizontal HIV transmission [22-25]. It is based on these recommendations that the researchers were motivated to carry out this study to contribute a quota to the realization of these goals.

The benefits of assessing the reproductive intentions of HIV-positive women cannot be overemphasized. There is need to assist HIV-positive women who desire to have children to do so with minimal risks to themselves, their children, and spouses. There is also the need to encourage HIVpositive women to adopt family planning practices especially condom use. This study was carried out to compliment the few studies on fertility desires of HIV-positive women in southeast Nigeria. The study aimed to examine the factors that influence HIV-positive women's desire to have more children with the intention of discouraging those that pose threats to their wellbeing.

\section{Materials and Method}

The study was conducted among 250 married HIV-positive women between the ages of 15 and 49 years who attended the "Heart to Heart" clinic in the Abia State University Teaching Hospital between the months of February and October 2013. Abia State University Teaching Hospital is the only tertiary and referral health center that serves HIV-positive individuals in Abia State and its environs. The antiretroviral treatment (ART) offered in this center is jointly supported by the Family Health International and is offered free to clients. Using this center afforded the researchers the opportunity of getting enough sample for the study. The services in this center especially ART are highly patronized. An average of $30 \mathrm{HIV}$-positive patients access ART services daily and over $50 \%$ of them are married females. The need to assist HIVpositive women who desire to have more children to do so with minimal risks to themselves, their children and spouses prompted the researchers to carry out this research.

This longitudinal cross-sectional descriptive study adopted systematic sampling technique. In this study, every third married female client between the age ranges of 15 and 49 years who came for Heart to Heart treatment within the study period (February to October 2013) was included in the study. A sample of 250 married women was 
studied. The sample size was calculated using the expression: $N=Z^{2}(100-p) p / d^{2}$; where $Z$ is a standard normal deviate, set at 1.96 . The prevalence of $20 \%$ HIV-positive women who desire to have children in sub-Saharan Africa confidence level was specified as $95 \%$ and the tolerable error margin $(d)$ was 5\% [19] was utilized.

The instruments for data collection were questionnaire and focus group discussions. Four focus group discussions which lasted for 30 minutes each were conducted. During the focus group discussion, reasons for desiring more children, benefits of using family planning practices especially condom and the risks of having more children were highlighted. The questionnaire which was semistructured was administered by well-trained research assistants. This was to ensure uniformity in the data collected. The sample constituted mainly of women in the low educational background. It was assumed that a good number of them may not be competent to complete the questionnaire correctly on their own.

Data were analyzed with the aid of SPSS version 17 software using descriptive and inferential statistics. Frequencies and proportions were presented in tables; Chisquare $\left(X^{2}\right)$ test was used to determine associations between categorical variables while logistic regression analysis was used to identify predictor factors for reproductive health intentions. Adjustment was made for predictor variables that were significantly related to the outcome variable at the bivariate level.

2.1. Quality Control. The questionnaire was pretested and administered by well-trained female research assistants. The female research assistants were used to encourage frank and open-minded discussions with the respondents so as to ensure collection of acceptable quality information. To minimize error, the interviewers used both English and local language to administer the questions to the sample. Also all unclear questions were explained to the sample and data were checked for completeness and accuracy before analysis.

2.2. Ethical Considerations. Informed consent was obtained verbally from the respondents after explaining the objectives of the study. All the respondents who positively consented to participate in the study were included. Ethical clearance was obtained from the Ethical Review committee of the Abia State University Teaching Hospital before starting the study.

\section{Results}

Out of the 250 questionnaires administered, two were inaccurately filled and were excluded from the study. Therefore, 248 questionnaires were analyzed.

3.1. Background Characteristics of the Respondents. The ages of the respondents were varied with the mean age of $36.1 \pm 8.5$ years. The greater proportions of the respondents were between the ages of 30 to 39 years. More than half of the respondents 135 (54.4\%) had secondary school education while $54(21.8 \%)$ had tertiary education. The rest had primary and no formal education. The monthly income of a greater
TABLE 1: Sociodemographic characteristics of respondents.

\begin{tabular}{lc}
\hline & Frequency $(\%)$ \\
\hline Age (years) & \\
Less than 25 & $11(4.4)$ \\
$25-29$ & $34(14.4)$ \\
$30-34$ & $73(29.4)$ \\
$35-39$ & $63(25.2)$ \\
$40-44$ & $28(11.2)$ \\
44 years and above & $39(15.6)$ \\
Total & $\mathbf{2 4 8}(\mathbf{1 0 0})$ \\
Level of education & \\
No formal education & $10(4.0)$ \\
Primary & $49(19.8)$ \\
Secondary & $135(54.4)$ \\
Tertiary & $54(21.8)$ \\
Total & $\mathbf{2 4 8}(\mathbf{1 0 0})$ \\
Occupation & \\
Housewife & $80(32.3)$ \\
Business & $140(56.4)$ \\
Civil servant & $18(7.3)$ \\
Teaching & $7(2.8)$ \\
Farming & $3(1.2)$ \\
Total & $\mathbf{2 4 8 ( 1 0 0 )}$ \\
No income & \\
Less than 72.37 & $57(23.03)$ \\
$72.37-131.58$ & $64(25.8)$ \\
138.16-197.37 & $76(30.6)$ \\
203.95-263.16 & $23(9.3)$ \\
M69.74-328.95 & $18(7.3)$ \\
Total & $4(1.6)$ \\
\hline
\end{tabular}

proportion of the respondents was below USD 300. In terms of religion, all the respondents were Christians. See Table 1 for more details on the background characteristics of the respondents.

The number of living children the respondents had was explored. From Table 2, a good number of the HIV-positive women had children ranging from one child to more than five children. Only 64 (25.8\%) of the women said they had no living child. See Table 2 for details. The number of respondents who desire to have children was noted.

From Table 3, a reasonable proportion of the respondents $158(63.7 \%)$ desired to have more babies. The reasons for desiring more children were explored.

3.2. Reasons for Desiring More Children. There were various reasons why the respondents desired more children. The focus group discussions showed that a good number of the respondents mainly those with no living child and those who said they need male children gave strong indications of desiring more babies. In the words of four respondents "I need babies at all cost. This will convince my husband and 
TABLE 2: Respondents and number of living children.

\begin{tabular}{lc}
\hline Number of living children & Responses \\
\hline None & $64(25.8 \%)$ \\
1 & $38(15.3 \%)$ \\
2 & $40(16.1 \%)$ \\
3 & $42(17.0 \%)$ \\
4 & $33(13.3 \%)$ \\
5 and above & $31(12.5 \%)$ \\
Mean & $\mathbf{2 . 3 \pm 4 . 7}$ \\
Total & $\mathbf{2 4 8 ( 1 0 0 \% )}$ \\
\hline
\end{tabular}

TABLE 3: Respondents and desire for more children.

\begin{tabular}{lc}
\hline Desire for more children & Frequency of response \\
\hline Yes & $158(63.7 \%)$ \\
No & $90(36.3 \%)$ \\
Total & $\mathbf{2 4 8 ( 1 0 0 \% )}$ \\
\hline
\end{tabular}

his relations that I am fertile. What is my gain if I do not have children in my marriage? It means that I am there in vain. I can be pushed out of the marriage anytime. God will not allow me to be barren. I shall be happy to have children even if I die in the process. Most of us are here to receive ART because we want to have children. Taking ART will help us get pregnant and have babies that are negative."

Majority of the HIV-positive women had some concerns about family planning practices. Five respondents saw family planning as a ploy to disrupt some marriages. "It is not easy for a married woman to suggest family planning especially condom use to a husband. If she does, she will be accused of infidelity. The ultimate punishment for infidelity is divorce which no woman ever prays for." Three respondents were of the view that "it is culturally wrong for a married woman to initiate family planning. It is the man's right to decide how many children the family needs. Women who mistakenly suggested condom use got their marriages in crisis." Six respondents felt that a woman who has no child after being married for more than a year has no moral justification to think of using family planning devices. In their words, "society expects every married woman to get pregnant immediately after marriage. If unfortunately a woman has no child or has only female children, she will be craving to have babies until she satisfies her desire of getting male children. The same is expected of her if she has only a son."

One respondent said "family planning especially condom use is synonymous with violence. If you want to lose your marriage or have constant conflict, just suggest using condom. Mother-in-laws are usually very aggressive when it comes to not having male issues. If you are unlucky they will arrange for women they feel will give birth to male children for their sons." A good number of the respondents had poor knowledge of the benefits of using family planning practices. Family planning especially condom use was mainly seen as a technique for preventing pregnancy. Only an insignificant number saw condom use as a means of protecting sex partners from being infected and reinfected.
TABLE 4: Respondents reasons for desiring to have children.

\begin{tabular}{lc}
\hline Respondents' reasons & Frequency \\
\hline To have right to husband's resources & $158(63.7 \%)$ \\
To fulfill the obligation of a woman & $158(63.7 \%)$ \\
To please my in-laws & $78(31.5 \%)$ \\
To consolidate my marriage & $63(25.4 \%)$ \\
To have those to take care of me at old age & $86(34.7 \%)$ \\
\hline
\end{tabular}

${ }^{*}$ Multiple responses.

At this juncture, the researchers enlightened the respondents on the benefits of using family planning devices especially condom. It was emphasized that condom use, in addition to preventing unwanted pregnancy, helps to protect sex partners from sexually transmitted infections including HIV. Table 4 shows other reasons the respondents had for desiring to have children.

From this table, a good proportion of the respondents, 158 (63.7\%), respectively, desired to have more children for the reasons of having right over husband's resources and fulfilling the obligation of a wife. See Table 4 for details.

The associations between the respondents' characteristics and the desire for babies were explored.

Table 5 shows that age, level of education, occupation, income, and number of living children have statistical significant associations with the desire for more children $(P=$ $0.001)$. The lower the respondents' age and parity the more they desired to have more children (OR 7.333, 95\% CI 0.596$89.470, P$ 0.001). Also the more the respondent has no living child, the more she desired to have more children. See Table 5 for more details. In the same vein, the less educated the respondents were, the less they desired to have more children (OR $0.387,95 \%$ CI $0.09-1.551, P 0.09$ ). It was necessary to note whether the respondents were aware of how they contracted HIV infection. This was to enlighten the respondents on the value of using family planning devices especially condom to protect self from infection and prevent unwanted pregnancy. In this circumstance, the respondents were asked whether they were aware of how they contracted HIV infection. The responses of the respondents are contained in Table 6.

From this Table, the respondents were knowledgeable of how they were infected. Only 117 (47.2\%) of the respondents could not tell how they were infected. See Table 6 for details.

\section{Discussion}

The fact that $63.7 \%$ of the women expressed the desire to have more children despite the fact that the mean number of living children was $2.3 \pm 4.7$ shows lack of knowledge of the value of family planning practices. It also shows lack of knowledge of the risks HIV-positive women are exposed to during pregnancy. This finding on lack of knowledge of pregnancy risks by HIV-positive women agrees with that conducted in other parts of Nigeria [18, 21], in Sub-Saharan Africa [22], and in Ontario, Canada [17]. The craving of women especially those between the ages of 25 and 29 years to have children just to satisfy husbands' desire for more children and to 
TABLE 5: Respondents' characteristics and the desire for more children.

\begin{tabular}{|c|c|c|c|c|}
\hline Variable & Odds ratio & S.E & $95 \% \mathrm{CI}$ & $P$ value \\
\hline \multicolumn{5}{|l|}{ Age (yrs) } \\
\hline \multicolumn{5}{|l|}{ Less than 25} \\
\hline $25-29$ & 7.333 & 1.280 & $0.596-89.47$ & 0.001 \\
\hline $30-34$ & 1.253 & 0.846 & $0.238-6.573$ & 0.3 \\
\hline $35-39$ & 0.295 & 0.820 & $0.059-1.475$ & 0.06 \\
\hline $40-44$ & 0.295 & 0.868 & $0.053-1.620$ & 0.08 \\
\hline 45 years and above & 0.012 & 1.063 & $0.0015-0.016$ & 0.001 \\
\hline \multicolumn{5}{|l|}{ Level of education } \\
\hline \multicolumn{5}{|l|}{ No formal education } \\
\hline Primary & 0.387 & 0.709 & $0.09-1.551$ & 0.09 \\
\hline Secondary & 1.833 & 0.674 & $0.489-6.868$ & 0.1 \\
\hline Tertiary & 1.228 & 0.704 & $0.309-4.874$ & 0.3 \\
\hline \multicolumn{5}{|c|}{ Number of living children } \\
\hline None & 6.786 & 0.533 & $3.983-11.977$ & 0.001 \\
\hline 1 & 3.691 & 0.546 & $2.138-6.373$ & 0.008 \\
\hline 2 & 2.5 & 0.506 & $0.927-6.740$ & 0.001 \\
\hline 3 & 0.917 & 0.459 & $0.373-2.52$ & 0.4 \\
\hline 4 and above & N/A & $\mathrm{N} / \mathrm{A}$ & N/A & \\
\hline \multicolumn{5}{|l|}{ Occupation } \\
\hline \multicolumn{5}{|l|}{${ }^{*}$ Housewife } \\
\hline Business & 1.353 & 0.293 & $0.760-2.401$ & 0.1 \\
\hline Civil servant & 0.299 & 0.55 & $0.166-0.537$ & 0.001 \\
\hline Teacher & 1.499 & 0.868 & $0.274-8.215$ & 0.32 \\
\hline Farming & $\mathrm{N} / \mathrm{A}$ & N/A & & \\
\hline
\end{tabular}

${ }^{*}$ Reference category.

TABLE 6: Respondents by knowledge of how HIV infection was contracted.

\begin{tabular}{lc}
\hline Knowledge of how HIV was contracted & Frequency (\%) \\
\hline Sexual means & $71(28.6)$ \\
Child birth & $14(5.6)$ \\
Blood transfusion & $28(11.2)$ \\
Sharing of sharps & $27(10.8)$ \\
Cannot tell & $117(47.2)$ \\
\hline
\end{tabular}

${ }^{*}$ Multiple responses.

consolidate the marriage points to the need for intensive family counseling for the families of HIV-positive women. It is necessary to health-educate the family members of HIVpositive women on the dangers of not encouraging them to limit the family size. This finding has implications on the quality of health care services rendered to HIV-positive women during ART clinics. The risks HIV-positive women are exposed to by not using family planning devices especially condom should form the integral part of health education to the women. This collaborates the views of previous studies $[21,23,24]$.

The findings in this study show that there are still unmet reproductive health needs of people living with HIV and AIDS even in Nigeria with high HIV prevalence. The fact that the respondents were still eager to have babies despite known health risks confirms this. There is absolute need for health care professionals to concentrate on providing health care services capable of preventing horizontal and vertical transmissions as well as reducing poor pregnancy outcomes especially for women with no living children. Comprehensive health education during counseling sessions has a role to play in shaping HIV-positive women's desire to have more children. Therefore, clinicians and other workers who counsel these patients should be as clear and simple as possible to impact and empower these women to make informed choices regarding their reproductive health decisions.

The finding that most HIV-positive women were on regular ART because of their desire to have children shows lack of knowledge of the benefits of regular ART in preventing vertical and horizontal transmissions. This finding is consistent with that of [21] which confirmed that a good proportion of women were on regular ARV because of their desire to have more children and not on the use of ART to reduce mother to child transmission (MTCT). The finding that HIVpositive women received regular ARV for the sole purpose of having more babies is important to developing countries especially those with high HIV prevalence in the prevention of mother to child transmission. A good number of the respondents had erroneous idea that regular ART will help to improve fertility. The finding is also important in enabling governments to make sound policies on pregnancy, delivery and breastfeeding for people living with HIV and AIDS so as 
to reduce MTCT. This finding is important because according to [1] as at the end of 2011 only $59 \%$ of pregnant women living with HIV in Sub-Saharan Africa received antiretroviral therapy for prevention of mother to child transmission of HIV.

The strong association between low parity and the desire for more children in this study is expected. In the African culture, the main purpose of marriage is procreation. Married women strive to fulfill this obligation so as to secure the marriage. The finding on the strong association between low parity and the desire to have more babies is consistent with that of [21].

The discussed results reflect an accurate summary of the behaviour of patients served at the Heart to Heart ART treatment center in Abia State. These results provide novel insight into the experiences of a large population of HIVpositive women seeking health care at a free ART clinic. Furthermore, the discussed results provided insights on how health care workers in ART clinics, clinic coordinators and other healthcare providers serving similar patient population could render improved health care services to the benefit of their clients. With the data on the reproductive health intentions of HIV-positive women, healthcare providers can anticipate the type of medical supplies, prescriptions, specialty medical staff, educators and other resources needed to provide the unmet needs of this population. The result has shown that provision of ART is not only the solution to the health crisis of HIV-positive women living in Abia State. There are other unmet needs that require attention. Therefore, the presented analysis could facilitate collaboration between policy-makers and healthcare providers to target funding for other services that would provide the unmet needs of married HIV-positive women. There should be sustainable solutions to deep-seated medical, political, and cultural issues facing HIV-positive women in the society.

The extent of poor knowledge the respondents exhibited on the importance of ARV and using family planning services especially condom calls for health workers to intensify regular family counseling and comprehensive health education during each encounter with HIV-positive individuals. This will help to equip them and their male partners with the techniques of keeping healthy so as to minimize infection and reinfection.

\section{Conflict of Interests}

The authors declare that there is no conflict of interests regarding the publication of this paper.

\section{References}

[1] UNAIDS, "2012 Report on the global AIDS epidemic," http:// www.unaids.org/en/.

[2] Federal Ministry of Health, "Technical report on the 2010 national HIV sentinel survey among pregnant women attending antenatal clinics in Nigeria," Tech. Rep., Ministry on Health, Abuja, Nigeria, 2012.
[3] UNDP HDR, "Country profile of human development indicators (Nigeria)," International Human Development Indicators, 2010, http://hdr.undp.org/en/countries/profiles/NGA.

[4] Federal Republic of Nigeria Official Gazette, 2007.

[5] J. L. Chen, K. A. Phillips, D. E. Kanouse, R. L. Collins, and A. Miu, "Fertility desires and intentions of HIV-positive men and women," Family Planning Perspectives, vol. 33, no. 4, pp. 144-165, 2001.

[6] J. Klein, J. E. Peña, M. H. Thornton II, and M. V. Sauer, "Understanding the motivations, concerns, and desires of human immunodeficiency virus 1-serodiscordant couples wishing to have children through assisted reproduction," Obstetrics and Gynecology, vol. 101, no. 5, pp. 987-994, 2003.

[7] B. Tonwe-Gold, D. K. Ekouevi, I. Viho et al., "Antiretroviral treatment and prevention of peripartum and postnatal HIV transmission in West Africa: evaluation of a two-tiered approach," PLoS Medicine, vol. 4, no. 8, article e257, 2007.

[8] V. Ndlovu, "Considering childbearing in the age of highly active antiretroviral therapy (HAART): views of HIV-positive couples," SAHARA-J, vol. 6, no. 2, pp. 58-68, 2009.

[9] K. Siegel and E. W. Schrimshaw, "Reasons and justifications for considering pregnancy among women living with HIV/aids," Psychology of Women Quarterly, vol. 25, no. 2, pp. 112-123, 2001.

[10] "HIV positive women have different needs," Network, vol. 20, no. $4,2001$.

[11] G. Degu, G. Yimer, Y. Berhane et al., "Reproductive health needs of PLWHA on ART," in Proceedings of the International Conference on Linking Reproductive Health, Family Planning and HIV/AIDS in Africa, Addis Ababa, Ethiopia, October 2006.

[12] J. M. Stephenson and A. Griffioen, "The effect of HIV diagnosis on reproductive experience," AIDS, vol. 10, no. 14, pp. 1683-1687, 1996.

[13] Y. Wesley, "Desire for children among black women with and without HIV infection," Journal of Nursing Scholarship, vol. 35, no. 1, pp. 37-43, 2003.

[14] D. Cooper, J. Moodley, V. Zweigenthal, L.-G. Bekker, I. Shah, and L. Myer, "Fertility intentions and reproductive health care needs of people living with HIV in Cape Town, South Africa: implications for integrating reproductive health and HIV care services," AIDS and Behavior, vol. 13, no. 1, supplement, pp. 3846, 2009.

[15] J. Mclytyre, "Strategies to protect mother-to-child transmission of HIV," Current Opinion in Infectious Diseases, vol. 19, no. 1, pp. 33-38, 2006.

[16] M. A. Magadi and A. O. Agwanda, "Investigating the association between HIV/AIDS and recent fertility patterns in Kenya," Social Science and Medicine, vol. 71, no. 2, pp. 335-344, 2010.

[17] M. R. Loutfy, T. A. Hart, S. S. Mohammed et al., "Fertility desires and intentions of HIV-positive women of reproductive age in Ontario, Canada: a cross-sectional study," PLoS One, vol. 4, no. 12, Article ID e7925, 2009.

[18] O. T. Oladapo, O. J. Daniel, O. L. Odusoga, and O. AyoolaSotubo, "Fertility desires and intentions of HIV-positive patients at a suburban specialist center," Journal of the National Medical Association, vol. 97, no. 12, pp. 1672-1681, 2005.

[19] B. Nattabi, J. Li, S. C. Thompson, C. G. Orach, and J. Earnest, "A systematic review of factors influencing fertility desires and intentions among people living with HIV/AIDS: implications 
for policy and service delivery," AIDS and Behavior, vol. 13, no. 5, pp. 949-968, 2009.

[20] SPSS 17.0., Statistical package for the Social sciences, Release 17. 0. 1, SPSS, 2008.

[21] Z. Iliyasu, I. S. Abubakar, M. Kabir, M. Babashani, F. Shuaib, and M. H. Aliyu, "Correlates of fertility intentions among HIV/AIDS patients in Northern Nigeria," African Journal of Reproductive Health, vol. 13, no. 3, pp. 71-83, 2009.

[22] J. Beyeza-Kashesya, F. Kaharuza, F. Mirembe, S. Neema, A. M. Ekstrom, and A. Kulane, "The dilemma of safe sex and having children: challenges facing HIV sero-discordant couples in Uganda," African Health Sciences, vol. 9, no. 1, pp. 2-12, 2009.

[23] K. Peltzer, L.-W. Chao, and P. Dana, "Family planning among HIV positive and negative Prevention of Mother to Child Transmission (PMTCT) clients in a resource poor setting in South Africa," AIDS and Behavior, vol. 13, no. 5, pp. 973-979, 2009.

[24] S. Kanniappan, M. J. Jeyapaul, and S. Kalyanwala, "Desire for motherhood: exploring HIV-positive women's desires, intentions and decision-making in attaining motherhood," AIDS Care, vol. 20, no. 6, pp. 625-630, 2008.

[25] T. Melesse, N. Damen, and M. Getnet, "Fertility intention in the era of HIV/AIDS among rural women in Bure Woreda, West Gojam, Amhara Region, Ethiopia," Educational Research, vol. 3, no. 4, pp. 380-387, 2012. 


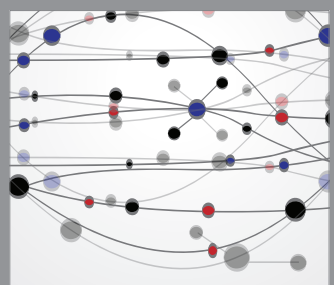

The Scientific World Journal
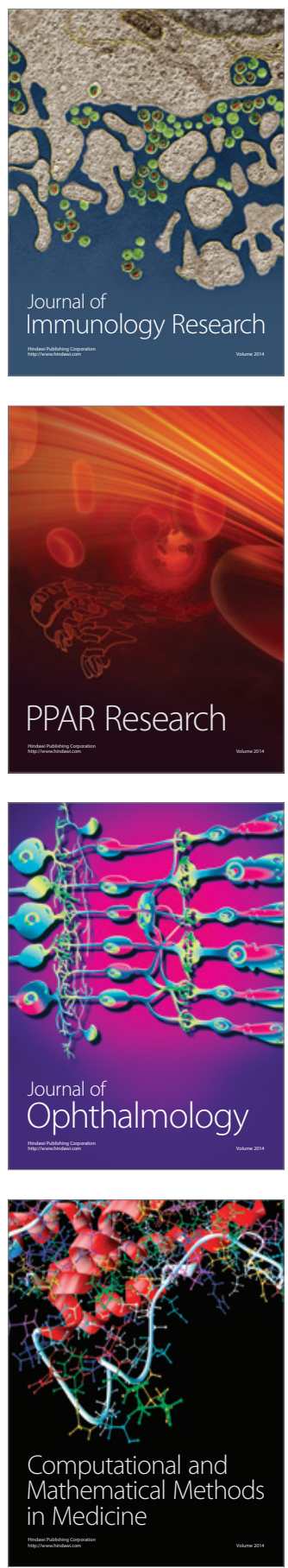

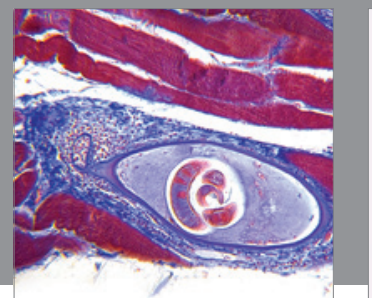

Gastroenterology

Research and Practice
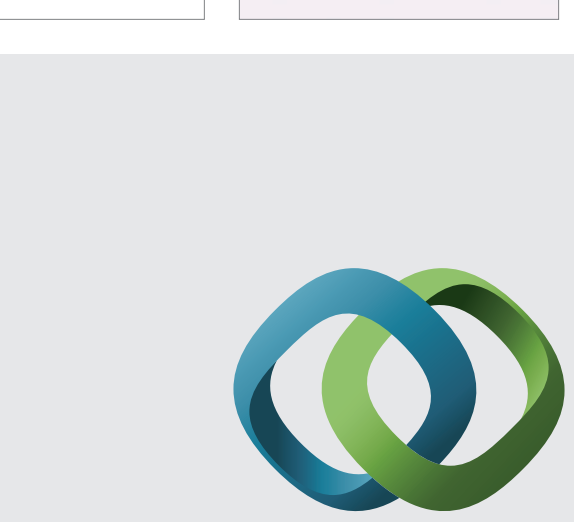

\section{Hindawi}

Submit your manuscripts at

http://www.hindawi.com
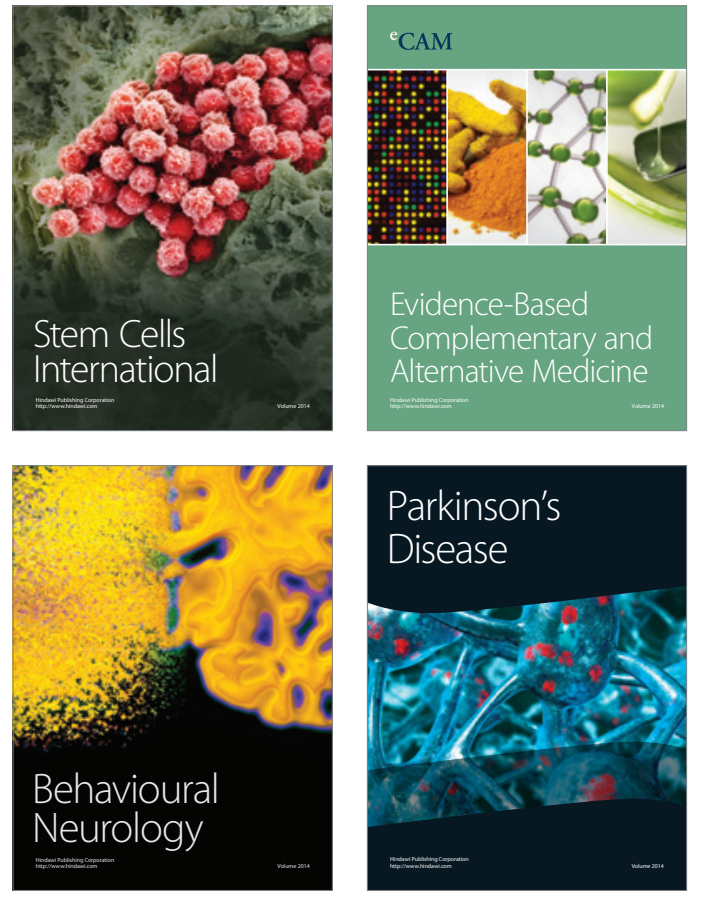
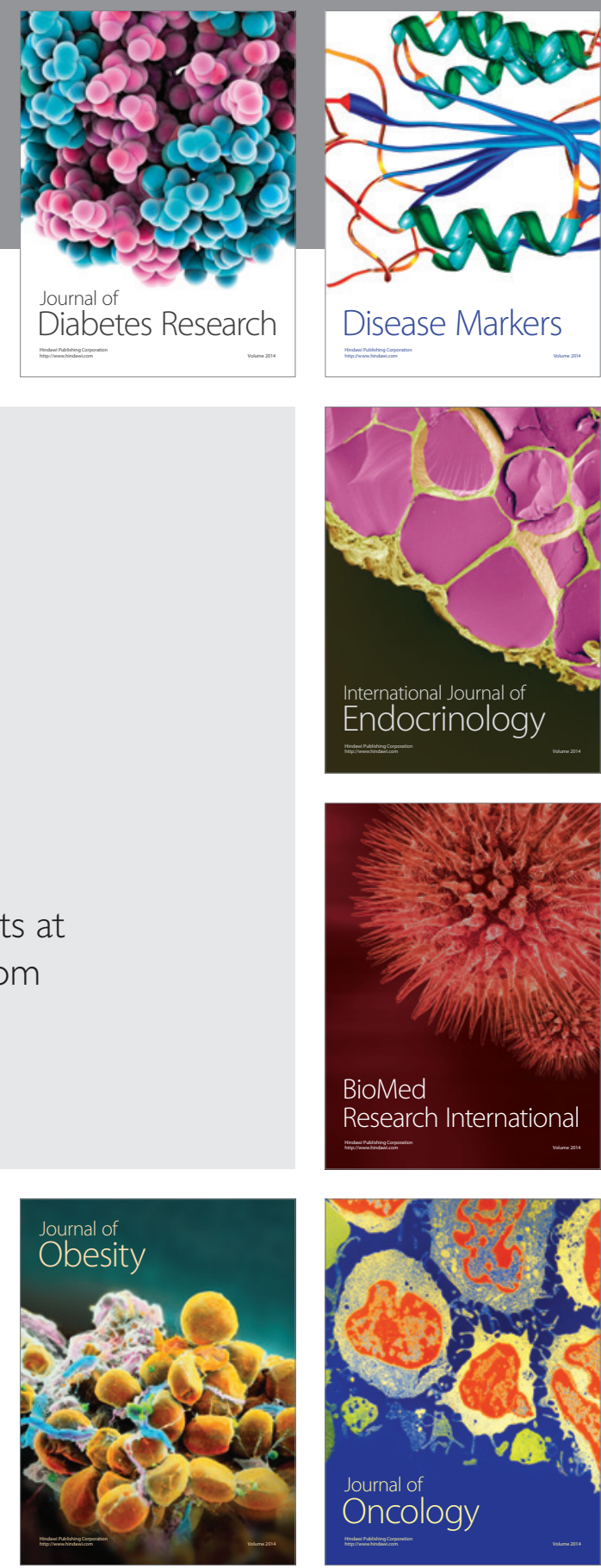

Disease Markers
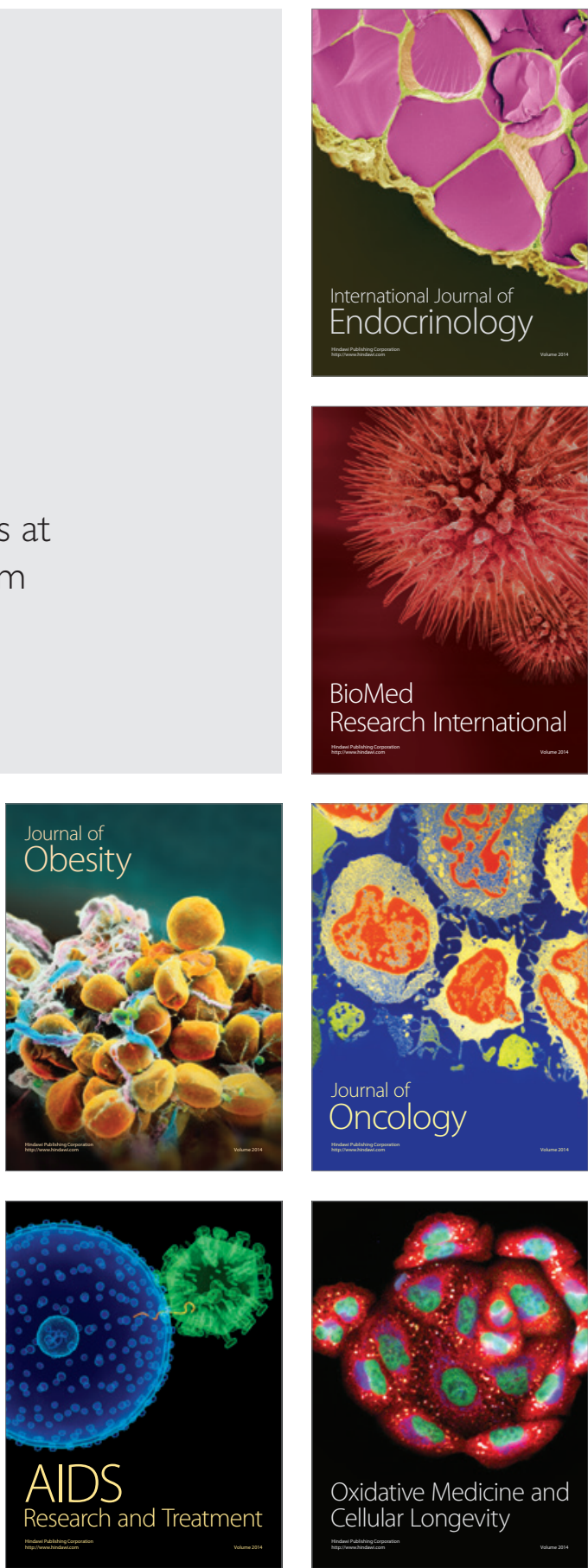